\title{
Testing Stochastic Convergence among Mexican States: A Polynomial Regression Analysis
}

\author{
Vicente German-Soto* and Natalia Salazar Garza
}

Faculty of Economics, Autonomous University of Coahuila, México

\begin{abstract}
Another look on the economic convergence among Mexican states is offered examining whether they are approaching along 1940-2010. Methodology is based on polynomial regressions, a method that determines whether predictions can be significantly improved by increasing the complexity of the fitted straight-line model. Estimates from a set of polynomial terms are a theoretical approximation to income differentials, so it constitutes an adequate frame to analyze if different initial conditions tend to diminish in the long-run. We calibrate for each economy the polynomial equation of best adjustment supported in information criteria and a strategy of backward iterative elimination. Empirical results are according with the stochastic convergence, but in a relationship where it changed after trade opening, poorer states are diverging and richer states are converging. A focalized regional policy is necessary with the aim to correct the biases produced in a context where some regions are lagging while others more are advancing.
\end{abstract}

Keywords: Convergence, polynomial regression, economic growth, Mexican states.

\section{INTRODUCTION}

The concept of convergence is related to the process of how a set of economies with similar characteristics are approaching its income levels in time. If economies converge to the income level of one leading economy, regardless the initial conditions, then is said that absolute convergence occurs. By the contrary, if the initial conditions matter and each economy trends to converge at its proper steady-state, then the conditional convergence occurs (Barro and Sala-i-Martin, 1991; Mankiw, Romer and Weil, 1992; among others). In this work the interest is in the stochastic convergence, a concept supported in the analysis of the statistical properties of the time series (Carlino and Mills, 1993; Bernard and Durlauf, 1995; Evans and Karras, 1996; among others). If mean, variance and covariance of the time series are kept constant in the time, after to control by serial correlation, is said that stochastic convergence occurs and it is a convenient way to demonstrate that income disparities, for example, trend to diminish in time ( $\mathrm{Li}$ and Papell, 1999; Yau and Hueng, 2007; among others). One advantage of the time series approach is that it allows us to consider the convergence properties of each region relative to the national average (Hammond, 2006).

The economic convergence, or a lack of it, has important implications for science, governments, economies, and for the society in general. If societies

\footnotetext{
*Address correspondence to this author at the Faculty of Economics, Autonomous University of Coahuila, Unidad Camporredondo, Edificio "E", Planta Baja, entre las calles Av. De los Maestros y David Berlanga, C.P. 25000, Saltillo, Coahuila, México; Tel: +52 84441287 82; Fax: +52 844410 26 79; E-mail: vicentegerman@uadec.edu.mx
}

evolve with lags while other exhibit great leads in terms of economic growth and progress in a way such that lagged societies do not have the possibility to catch-up the leaders, then the economic growth theory would be incomplete because it means that it is only valid for some countries, but not for others, a precept that is hard to accept.

In a regional context, the economic convergence seeks to analyze if a set of economies sharing the same objectives, equal government policies, the currency and rate of exchange, that is the identical macroeconomic frame, are or not converging. If none tendency is found to equalize their average incomes then some regions are advancing while others are lagging with consequences on a uniform regional development. In addition, an unequal development of the regions of one country could be related with a lack of growing, affecting the power purchasing of the inhabitants and promoting the economic differences among regions, an adverse result for the government and the society.

The aim of this work is to study the convergence process of the Mexican states along 1940-2010 and to check if some relationship exists among those regions that possibly are not converging and their performance in terms of relative regional income. With this purpose a polynomial regression model is adjusted for each region, where the evolution of the differentials of per capita gross domestic product (GDP) is tested to show a tendency to fall in time. The hypothesis is that a process of regional convergence exists, but it has not been uniform due to atypical events that broke the tendency towards the convergence, as a result it is possible that some states would have changed their 
tendency. So, a focalized regional policy is necessary with the aim to correct the biases produced in a context where some regions are lagging while others more are advancing.

In Mexico it is possible to access to one quite complete database at the state level. In specific, German-Soto's web provides a long and updated database that allows conducting studies on economic growth and convergence of the Mexican states. ${ }^{1}$ In spite that official institutes collecting the economic statistical in Mexico are a good point of reference, the German-Soto's database has the advantage to cover a long period of homogenous figures making easier the studies on this field. Actually, a great amount of works has tested his database. Technical details about its construction and methodology of estimation can be consulted in German-Soto (2005), for the figures on gross state product, German-Soto (2008), for figures on physical capital stock, and German-Soto, Rodríguez and Escamilla (2013), for calculus on human capital indexes. This study is supported in those databases.

Beside this introduction, the work is developed in four sections. The first one makes a review of literature on convergence. Section two explains the polynomial regression approach. Section three introduces the database and comments the results of the regressions. Section four treats the conclusions and the main findings.

\section{LITERATURE REVIEW}

The economic growth is a relevant field of study with great importance for governments, researchers, people, and entrepreneurs and practically for the social sciences, because it implies increases in the production and the variety of goods and services for consumption of the society. It is considered as a precondition to development and its implications such as the lack of growth of some economies, the unequal distribution of incomes and the also unequal development of the economies along the time are widely studied and analyzed since the times of the classical as Smith, Ricardo, Mills, Schumpeter, Keynes, among others.

Smith called the attention on the division of the labor and specialization as main determinants about the economic growth of the nations. Ricardo

${ }^{1}$ Database is available from his web-page: http://works.bepress.com/vicente_ german_soto. See section of 'Courses'. emphasized on the importance of the international trade as key cause of growing. Schumpeter expanded the borders of the Economics science viewing on the role of the innovation, the role of entrepreneurs and the agglomeration forces of the economies. More recently, by the XX century, Keynes turned the economic vision on investment variations in the short term (Guerrieri, 1990).

In the present day, a rising subject is the study of the economic convergence, a quite related concept to economic growth because it is concerned with the process of reduction of the per capita income differences among a set of economies in the long-run. Its relevance coming from some stylized facts about the modern economies in relation to its performance on economic growth: increases in per capita GDP forming a positive tendency that are observed in the long-run and as a result, the posterior abandoning of the precepts that were considered by the cyclical behaviors, that is, the analyses in the long-run acquire more importance (Barberá and Doncel, 2003; Barro and Sala-i-Martin, 2004, among others). A set of reasons has highlighted the generation of analyses on convergence, some of them are the improvements of technologies on collection of data, the advances in software and computer science that make possible a great amount of calculus and permit the testing of a great variety of methods and models. As a result, many of the theoretical models that in other times remained as theoretical proposals can be empirically tested in the actually. The economic growth and the economic convergence are some good examples about it.

The theoretical bases of the economic convergence start from the ideas of Solow (1956) who was concerned about the determinants and sources of the economic growth. According to his theory, as consequence of the dynamics of growing of its main factors, such as the labor and physical capital, the economic growth trends to exhibit decreasing returns when the investment of some of these factors is augmented. In this framework, increments of physical capital for initial stages will lead to increases the productivity, but interestingly these increments will be increasingly smaller in the long-run until they get to a stage where they become stationary. Assuming that technological progress is absent, the poorer economies will have the opportunity to reach the standard of development reached by the richer economies, that is to say, it will be convergence (Jones, 2000).

The idea of the convergence has been quite studied in the most recent decades and actually we can to 
identify some theoretical positions about the argument that in the long-run the gap of economic growth will be closed: defenders of the exogenous economic growth affirm that convergence is a possible scenery (Mankiw, Romer and Weil, 1992; Islam, 1995; Nonneman and Vanhoudt, 1996; among others), on the contrary, some authors consider that more that convergence a process of divergence exists, and the externalities and agglomeration forces increasing the differences (Romer, 1986; Lucas, 1988; Grossman and Helpman,1991, among others), while a variety of positions can be found among them. First, one current finds that world economies evolve as convergence clubs, that is only some countries are in clear process of convergence, regularly the more developed countries, while other are in divergence, therefore some clubs of countries with similar results are forming, but an overall process of convergence is not seem the norm (some classical works are Chatterji, 1992; Quah, 1996; Berthelemy and Varoudakis, 1996; Bianchi, 1997; Ben-David, 1998; Hobijn and Franses, 2000; Deardorff, 2001; among others). Second, some others have found the formation of common trends, but little few evidence of convergence (Bernard and Durlauf, 1995), while others highlight that economies are in a poverty trap (Azariadis, 1996 and Crafts, 1999).

While discussion about convergence is not fully finished, several works have emphasized on the structural aspects of the data and tools used to test the existence of such process. To mention some of them, on the one hand are the proposals that argue that as consequence that convergence is a phenomenon in the long-run, the time series suffers of diverse troubles such as no attended serial correlation, structural breaks occurring in one moment of the analysis period and other additional statistical limitations (Lee, Pesaran and Smith, 1997). In general, these works have found that after to control by differences in the steady-state, by the presence of possible structural breaks and correcting by serial correlation is possible to conclude about stationarity of the time series, it means favorable evidence that a process of convergence is occurring, but one characterized by broken tendencies by one or more structural changes that modified the dynamics to equalize the per capita incomes among the economies. Other vein of research, which is gaining popularity, considers that spatial effects must be fundamental to give more precise juices about convergence (Rey and Montouri, 1999; Badinger, Müller and Tondl, 2004; Ertur, Le Gallo and Baumont, 2006; Fischer, 2011; Lu and Wang, 2015, among others). The idea is that production and so per capita incomes of an economy are not determined in isolation because economic activity depends of the proper economy characteristics, but also depends of the performance of the economies with which it is social and economically related, so the concept of neighboring is a factor to take into account for this methodological approach. In general, results from tools that consider the spatial effects of the neighbors are in the line on the existence of a convergence process once that spatial effects are included in the regression equation used to test the theory of convergence.

This work is situated on the perspective of the time series analyses. So, it is directed to analyze this process along time, therefore aspects as serial correlation and the presence of structural breaks will be fundamental to sustain the conclusions. The methodology rests on the polynomial regression approach, a technique based on the analysis, through a regression equation, of the per capita income gap evolution. The polynomial approach designs a model polynomial regression that best adjustment to the income gap from each economy. The proposal is in line with previous works (see Nahar and Inder, 2002, German-Soto, 2013) and it will consider the typical problems of serial correlation and the presence of breakpoints. In the next section we are comment the details of this methodology.

\section{THE POLYNOMIAL REGRESSION APPROACH}

The theory on time series argues that temporal data is characterized by the denominated ARIMA processes (integrated autoregressive terms with processes of moving average) because also each time series is composed by several polynomial degrees, which can be treated as lag, seasonal, subjacent adaptive, rational, among others.

As a particular case of multiple regression, the polynomial regression is defined by the several orders or degrees of the explicative variable, such a way that the model consists in a regression equation with a set of independent variables, one by each polynomial degree included in the model. Similar considerations applied to standard econometrics are also considered for this kind of regressions. For example, the assumption of fixed $X$, or not stochastic, is also assumed for $X$ at its different polynomial degrees. The simplest polynomial regression corresponds to the straight line, or the second order polynomial regression, which implies the consideration of the 
independent variables $X$ and $X^{2}$. So, adding high orders of $X$ gives place to polynomial regressions of high order. The aim is to reach the polynomial order of best adjustment in the relationship among dependent and independent variables.

Formally, the $k$ polynomial order in $x$ is defined as (Kleinbaum, Kupper, Nizam and Muller, 2008):

$y=c_{0}+c_{1} x+c_{2} x^{2}+\ldots+c_{k} x^{k}$

The corresponding stochastic definition of the equation (1) is:

$y=\beta_{0}+\beta_{1} x+\beta_{2} x^{2}+\ldots+\beta_{k} x^{k}+E$

where $E$ represents the stochastic error term. The aim is to determinate the parabola of best adjustment at the data, which can be done through ordinary least squares (OLS) or by means of maximum likelihood (ML) methods.

In particular, the polynomial order will dependent of the nature of the problem under study, the amount and type of data and also from the sample size. One advantage of the polynomial regression models is that it takes into account the augments and diminishes of the curve formed in the time because the several polynomial orders evaluate each peak of the curve, a behavior does not captured when a model of simple order is carry out. However, is necessary to consider that quantity of data limits the maximum order of a polynomial regression, due to evident loss of data implied by major polynomial orders. Other of the problems has to see with the correlation among explicative variables arising with the aggregation of major number of polynomial degrees. In the extreme, it would imply important problems of multicollinearity.

\subsection{Some Technical Details Estimating Polynomial Regressions}

One of the fundamental decisions with polynomial regressions is what method should be adopted to select the order of polynomial of the best adjustment. For this case we follow the strategy of backward iterative elimination suggested in other works (Kleimbaum, et al. 2008; $\mathrm{Ng}$ and Perron, 2001, among others). The idea consists in to start with a high polynomial order and so iteratively eliminate the not significant polynomial orders and to stop until to find the statistically significant higher polynomial degree, in this point all minor polynomial orders should take into account as the model of best adjustment. The necessity of high orders in the polynomial obeys to the non-linear tendency of residuals. It has been demonstrated that backward strategy yield best results that other different strategies (see, for example, $\mathrm{Ng}$ and Perron, 1995 and 2001).

Significance level to select the maximum order of polynomial is decided in a composed $t$-student test, as follows:

$$
t_{c}=\frac{\hat{\beta}_{1}+\hat{\beta}_{2}+\ldots \hat{\beta}_{k}}{\sqrt{\operatorname{var}\left(\hat{\beta}_{1}\right)+\operatorname{var}\left(\hat{\beta}_{2}\right)+\ldots+\operatorname{var}\left(\hat{\beta}_{k}\right)+2 \operatorname{cov}\left(\hat{\beta}_{1}, \hat{\beta}_{2}\right)+\ldots}}
$$

where $k$ represents the maximum order of polynomial. Using some level of significance it is possible to decide about the significance of each polynomial term. In the possibility that two or more polynomial model would be significant a Schwarz information criterion (SIC) is used to decide among them, such as is recommended by Montañés, Olloqui and Calvo (2005):

$S I C=n^{2 k / n}=\frac{R S S}{n}$

where RSS is the residual sum of squares, $n$ is the size of the sample and $k$ is the highest polynomial term. We can essay other information criteria as the Akaike, for example, but it is demonstrated that SIC yields better results because it imposes a penalty by the major number of variables included in the model.

\subsection{Methodology of Empirical Strategy}

Nahar and Inder (2002) introduce this methodology to measure the economic convergence among 22 OECD countries, in a structure where the gap in per capita GDP is analyzed in a regression equation with polynomial terms. If a process of convergence exists, then the differences in per capita GDP with respect to one benchmark should trend at one constant value in the long-run. Formally,

$\lim _{n \rightarrow \infty} E_{t}\left(y_{i, t+n}-a_{t+n}\right)=\mu_{i}$

where $\mu$ is determined by the level of the economy $i$, which will be different to zero insofar as economies have also different structures. The benchmark $a_{t}$ can be defined as the average of per capita GDP of all regions or as per capita GDP of the group leader, that is, the income of the region or country with the best 
economic performance. Finally, for each economy, $y_{i t}$ is the per capita GDP in logarithmic terms. In this case, the steady-state highlighted by the neoclassical theory is represented by one of the above benchmarks.

If $\mu_{i}$ is equal to zero in (5), then a process of absolute convergence is happening. In our empirical exercise integrated by a set of regions of the same country, we have not a clearly defined leader along the period. In this case the benchmark defined as the average per capita GDP of all regions is a more adequate benchmark. Therefore, the income differences defined in comparison to the average of the group are:

$\lim _{n \rightarrow \infty} E_{t}\left(y_{i, t+n}-\bar{y}_{t+n}\right)=\mu_{i}$

The squared of the absolute differences in (6), defined by $w_{i t}$, avoids treating with negative figures and allows that we concentrate in the gap and its evolution along time, then equation of empirical estimation is as follows:

$\lim _{n \rightarrow \infty} E_{t}\left(w_{i, t+n}\right)=0$

where $w_{i, t+n}=\left(y_{i, t+n}-\bar{y}_{t+n}\right)^{2}$. A convergence process is detected when $w_{i t}$ exhibits a negative slope and tends to zero, as is defined in (7). Therefore, the possibility of economic convergence can be assessed through the estimation of the slope of $w_{i t}$, in function of a linear tendency, $t$. This idea is expressed in the next equation of empirical investigation:

$w_{i t}=f(t)+u_{i t}=\theta_{0}+\theta_{1} t+\theta_{2} t^{2}+\ldots+\theta_{k-1} t^{k-1}+\theta_{k} t^{k}+u_{i t}$

where $f(t)$ is the assumed data generating process, $t$ is a measure of the linear trend, $k$ is the maximum order of the polynomial term, $\theta^{\prime} s$ are the parameters to be estimated and the $u_{i t}$ is the error term. From the equation (8) is easy to find the average slope through its first derivate:

$\frac{\partial}{\partial t} w_{i t}=f^{\prime}(t)$

Equation (9) will estimate negative values in the case of converging economies, that is, its slope will be negative.

Besides to directly obtain the speed of convergence, the use of data in logarithmic terms has the additional advantage to reduce the possible presence of multicollinearity. In addition, the transformation of per capita GDP as the differences with respect to the benchmark, also allows diminishing the collinearity among the polynomial terms.

\section{DATABASE AND RESULTS}

\subsection{Database Description}

Our study is carry out for the 32 federal Mexican states and covers the period of 1940 to 2010, a sufficiently large interval to apply the methodology of polynomial regressions. Database only requires two main socioeconomic variables for each federal entity: population and GDP. Those two variables allow calculating the corresponding variable that is object of study: the per capita GDP and its squared differences in comparison to the benchmark defined as the national average per capita income.

Availability of a so large time series is almost impossible from official sources in almost any country. Commonly, countries have GDP figures for large periods but often they are not comparable because changes in the base year or due to methodological changes, therefore some data processing is required. Fortunately, for Mexico homogenous and comparable figures of GDP were generated by German-Soto (2005) and updated to $2010^{2}$. Population figures used in this work also correspond to German-Soto's web page, they are considered by the author from National Council of Population (CONAPO). This way, figures on per capita GDP were possible for all states in a year-toyear base.

A first approximation to the convergence process among the Mexican states is explored in the Figure 1. Initially, the income gap was quite elevated in the set of states, while it is observed that differences were gradually falling out until the seventies, approximately. After that they seem to rise or, at least, they not seem to be diminishing.

This behavior is suggesting that the income gap of the Mexican states describes a trajectory where the trend changed from convergence to divergence or, at least, towards a situation where reductions of income differences have stopped. This observation is confirmed with the calculus of the sigma-convergence index. It analyses the trajectory of the standard

${ }^{2}$ See data in the web page of German-Soto: http://works.bepress.com/vicente german_soto. 


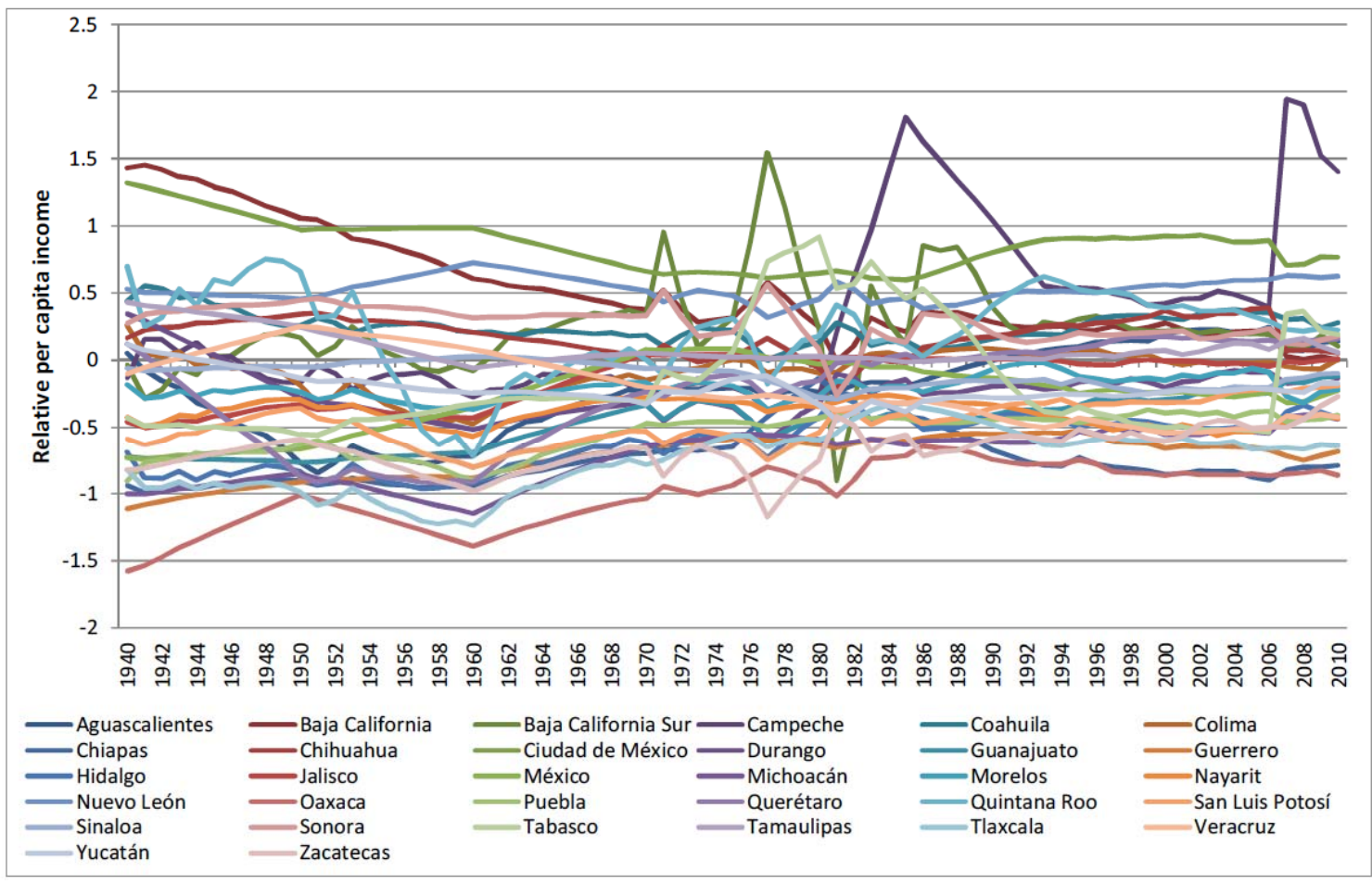

Figure 1: Income gap evolution of the 32 Mexican states, 1940-2010.

Source: own estimates from database.

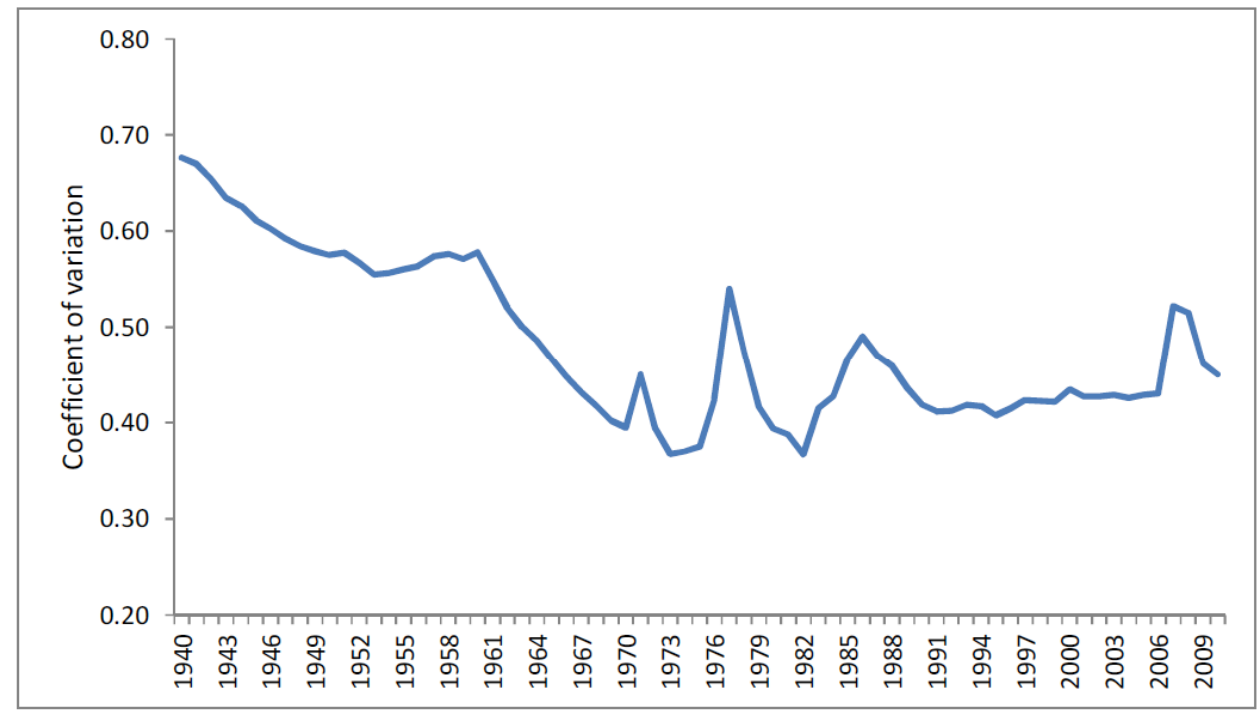

Figure 2: Sigma-convergence among Mexican states, 1940-2010.

Source: own estimates from database.

deviation of the income differences along the time. Figure 2 shows the sigma-convergence among Mexican states. Also from this point of view the gap of income trended to reduce along the first years of the period, after that the slope remains near horizontal, by the eighties, and finally it seems to increase.

Both Figures 1 and 2 offer a preliminary panorama about the dynamics of the Mexican regional convergence. The turn points by the seventies or eighties can be indicatives of the presence of structural breaks that should be taking into account in the exercises with polynomial regressions.

\subsection{Results}

Empirical results with the equations (8) and (9) are obtained for the overall period and the two stages that 
are possible to identify from the turn point highlighted by the Figures 1 and 2 . From simulation exercises we find that 1986 is the more appropriate year as breaking date among the all other alternatives. So, our sample is divided from this date with the end to compare the convergence dynamics in the two these different stages.
Table 1 reports the main results on convergence for overall period, 1940-2010, that is assuming a homogenous evolution of the income gap. For each state, Table 1 presents the polynomial order of best adjustment, the estimated slope and its sign, the tstatistic, according to equation (3), and the conclusion about the convergence exhibited along the overall period.

Table 1: Convergence Results among Mexican States, 1940-2010

\begin{tabular}{|c|c|c|c|}
\hline Federal entity & Polynomial degree & Average slope & $t$-statistic \\
\hline Aguascalientes & 8 & $-0.0005^{\star}$ & -2.403 \\
\hline Baja California & 10 & $0.0013^{*}$ & 2.715 \\
\hline Baja California Sur & 6 & 0.0012 & 1.086 \\
\hline Campeche & 9 & -0.0002 & -0.050 \\
\hline Coahuila & 10 & $0.0012^{*}$ & 4.129 \\
\hline Colima & 10 & -0.000 & -0.208 \\
\hline Chiapas & 10 & 0.000 & 0.024 \\
\hline Chihuahua & 9 & $0.0003^{*}$ & 1.740 \\
\hline Ciudad de México & 10 & $0.0017^{*}$ & 1.927 \\
\hline Durango & 10 & 0.000 & -0.086 \\
\hline Guanajuato & 7 & -0.0004 & -1.599 \\
\hline Guerrero & 8 & $-0.001^{*}$ & -3.644 \\
\hline Hidalgo & 9 & $0.0014^{*}$ & 2.125 \\
\hline Jalisco & 10 & 0.0000 & 0.333 \\
\hline Estado de México & 9 & $-0.0009^{*}$ & -6.524 \\
\hline Michoacán & 10 & -0.0003 & -0.942 \\
\hline Morelos & 10 & 0.0004 & 1.381 \\
\hline Nayarit & 10 & 0.003 & 1.095 \\
\hline Nuevo León & 9 & $0.0015^{*}$ & 2.683 \\
\hline Oaxaca & 9 & $-0.0016^{\star}$ & -2.973 \\
\hline Puebla & 8 & $-0.0014^{*}$ & -4.086 \\
\hline Querétaro & 9 & $-0.0008^{*}$ & -2.841 \\
\hline Quintana Roo & 9 & $-0.0016^{*}$ & -1.960 \\
\hline San Luis Potosí & 9 & 0.0002 & 0.334 \\
\hline Sinaloa & 10 & 0.0000 & 0.389 \\
\hline Sonora & 4 & $0.0005^{\star}$ & 8.281 \\
\hline Tabasco & 9 & 0.0012 & 1.276 \\
\hline Tamaulipas & 6 & 0.0000 & 1.276 \\
\hline Tlaxcala & 10 & $0.0027^{*}$ & 4.088 \\
\hline Veracruz & 7 & $-0.0004^{*}$ & -4.717 \\
\hline Yucatán & 10 & -0.0002 & -0.919 \\
\hline Zacatecas & 4 & $-0.0009^{*}$ & -3.588 \\
\hline
\end{tabular}


It is observed that 17 states have significant results on stochastic convergence. However, some states are converging while others more are diverging, according with the estimated sign of its average slope. States in a clear convergence are: Aguascalientes, Guerrero, Estado de México, Oaxaca, Puebla, Quintana Roo, Querétaro, Veracruz and Zacatecas. On the other hand, diverging states are: Baja California, Chihuahua, Coahuila, Ciudad de México ${ }^{3}$, Hidalgo, Nuevo León, Sonora and Tlaxcala.

As additional information supporting the results on convergence it is appreciated that states in convergence are a mixture of poorer and middleincome states. For example, three of the poorer states are Guerrero, Oaxaca and Puebla, while three states of middle-income are Aguascalientes, Querétaro and Zacatecas. In addition, from the set of diverging states outstand the richer and also located in the NorthFrontier: Baja California, Chihuahua, Nuevo León and Sonora (states of the North-Frontier and with major levels of income), while Ciudad de México belongs to the richer group.

The estimated coefficient of slope would be interpreted as the speed at which each economy is approximating to the benchmark. For example, Guerrero is one state essaying a convergence process because the slope was estimated as negative and significant. The absolute value is equal to 0.0011 indicating that this state has been reducing its gap at speed of 0.11 percent by year. Hidalgo is a state where the estimated coefficient was negative and equal to 0.0014 , in absolute terms. It means that this state is moving away at the speed of 0.14 percent by year.

Analyses for Mexico yield best results when the presence of structural changes is taken into account due to frequent macroeconomic events that have modified the tendency of the variables. From the Figures 1 and 2 we have already documented this fact. In the eighties, the country averaged a rate of growth equal to zero, even negative in some years of that decade; also the presence of crises between 1982 and 1988 importantly affected the macroeconomic scope. As a result many socioeconomic variables changed its tendency and the possible structural changes are relevant in studies of this nature.

After several essays to know the best location of the structural break we have found that 1986 is the most

${ }^{3}$ Distrito Federal, actually known as Ciudad de México. adequate, so we analyze the convergence process in the two stages divided by 1986: the first stage between 1940 and 1986 and the second one between 1986 and 2010. Results for the first stage are shown in the Table 2. It is observed that 14 states had statistically significant estimates on the slope.

According to Table 2 states in a clear tendency to diverge are: Coahuila, Hidalgo, Morelos, Tamaulipas and Tlaxcala. By the contrary, the set of converging states are: Colima, Guerrero, Jalisco, México, Michoacán, Oaxaca, Puebla, Quintana Roo and Sinaloa.

While results on poor and rich states are mixed, the set of states in convergence in this first stage are more identified as poorer states, this is the case of Guerrero, Michoacán, Oaxaca and Puebla. This observation has relevant consequences of economic policy because is indicating that policies of public expenditure, which was abundant and extensive in those years, with objectives to create favorable conditions to industrialize the nation and to improve the infrastructure such as electricity, roads, health, education, among others, they exerted effects that improved the equality among the states.

Results are shown in the Table $\mathbf{3}$ for the second stage. Also in this case 14 states were favorable to stochastic convergence, from which 11 states are converging: Campeche, Chiapas, Colima, Jalisco, México, Morelos, Puebla, San Luis Potosí, Tabasco, Tlaxcala and Yucatán. Differently, Baja California, Michoacán and Querétaro are diverging.

In resume, there are more cases in clear convergence in the second stage - in comparison to the first stage -, while evidence on stochastic convergence is nearly to the fifty percent of the sample. In the first stage 69 percent of the significant cases trended to converge, while only 31 percent was towards divergence. In change, for the second period, 78 percent of the federal entities with significant coefficient are converging, while 22 percent are in divergence. This means that convergence process is major in the second stage, a period characterized by major trade opening.

A depth analysis suggests a polarization process dominating in the distribution of per capita income among Mexican states. It is argued in the more favorable results towards convergence in a majority of the richer entities, while they are less favorable in the group of poor states. For example, Aguascalientes, 
Table 2: Convergence Results among Mexican States, 1940-1986

\begin{tabular}{|c|c|c|c|}
\hline Aguascalientes & 10 & 0.0006 & 0.691 \\
\hline Baja California Sur & 8 & -0.0027 & -0.503 \\
\hline Campeche & 10 & 0.0028 & 1.083 \\
\hline Colima & 9 & $-0.0005^{\star}$ & -2.495 \\
\hline Chiapas & 10 & 0.0004 & 1.338 \\
\hline Chihuahua & 9 & 0.0003 & 1.328 \\
\hline Ciudad de México & 10 & -0.0017 & -1.534 \\
\hline Hidalgo & 10 & $0.0045^{\star}$ & 2.929 \\
\hline Jalisco & 10 & $-0.0003^{*}$ & -2.378 \\
\hline Estado de México & 10 & $-0.0008^{*}$ & -5.101 \\
\hline Michoacán & 10 & $-0.0017^{*}$ & -3.897 \\
\hline Morelos & 10 & $0.0007^{*}$ & 1.681 \\
\hline Nayarit & 10 & 0.0003 & 0.933 \\
\hline Nuevo León & 9 & -0.0002 & -0.185 \\
\hline Oaxaca & 10 & $-0.0065^{*}$ & -6.477 \\
\hline Sonora & 7 & 0.0008 & 1.274 \\
\hline Tabasco & 9 & 0.0013 & 0.753 \\
\hline Tamaulipas & 9 & $0.0002^{*}$ & 2.185 \\
\hline Tlaxcala & 7 & $0.0024^{*}$ & 2.893 \\
\hline Veracruz & 10 & -0.0003 & -1.604 \\
\hline Yucatán & 8 & -0.000 & -0.028 \\
\hline Zacatecas & 8 & -0.0016 & -0.623 \\
\hline
\end{tabular}

Notes:* indicates significance at $10 \%$ or less.

Source: own elaboration.

Coahuila, Ciudad de México, Jalisco and Nuevo León are examples where per capita income has usually been more elevated. The technique also has identified these entities as cases of regional convergence.

On the other hand, states as Campeche, Durango, Guerrero, Hidalgo, Morelos, Nayarit and Yucatán are entities with per capita income usually inferior to the national average, while the technique also has assessed that this set of states has augmented the income gap because the estimated coefficient was statistically significant and with the right sign towards the divergence.

\section{CONCLUSIONS}

As happens with other technique or database, our results should be surely limited by some assumptions. 
Table 3: Convergence Results among Mexican States, 1986-2010

\begin{tabular}{|c|c|c|c|}
\hline Aguascalientes & 3 & -0.0273 & 0.000 \\
\hline Baja California Sur & 3 & -0.0978 & 0.000 \\
\hline Campeche & 5 & $-39.974^{*}$ & -1.778 \\
\hline Colima & 5 & $-0.7033^{*}$ & -3.098 \\
\hline Chiapas & 5 & $-3.825^{\star}$ & -2.424 \\
\hline Chihuahua & 3 & -0.0234 & 0.000 \\
\hline Ciudad de México & 2 & 0.0187 & 0.000 \\
\hline Hidalgo & 3 & -0.0513 & 0.000 \\
\hline Jalisco & 5 & $-0.3620^{*}$ & -2.683 \\
\hline Estado de México & 5 & $-2.356^{*}$ & -2.277 \\
\hline Michoacán & 4 & $0.2007^{*}$ & 2.605 \\
\hline Morelos & 5 & $-3.087^{*}$ & -2.468 \\
\hline Nayarit & 3 & -0.0276 & 0.000 \\
\hline Nuevo León & 2 & 0.0049 & 0.000 \\
\hline Oaxaca & 2 & -0.0011 & 0.000 \\
\hline Sonora & 3 & -0.00143 & 0.000 \\
\hline Tabasco & 4 & $-0.3452^{*}$ & -2.714 \\
\hline Tamaulipas & 3 & -0.0060 & 0.000 \\
\hline Tlaxcala & 5 & $-6.7788^{*}$ & -4.658 \\
\hline Veracruz & 3 & -0.0122 & 0.000 \\
\hline Yucatán & 5 & $-1.8658^{*}$ & -2.513 \\
\hline Zacatecas & 3 & -0.0673 & 0.000 \\
\hline
\end{tabular}

Notes:* indicates significance at $10 \%$ or less.

Source: own elaboration.

For example, the assumptions in the construction of the per capita GDP, the size of the sample and the restrictions of the polynomial regressions can to affect the results. In spite of, our results allow describing a very close panorama to performance of the state economies in the last seventy years. It gives a relative consistency on how the technique is generating results that harmonizing with the empirical facts.
The income inequality in Mexico must be matter of concern for the government and society because the present empirical exercise has documented that in the last decades the Mexican states are augmenting the income gap, mainly in the states geographically belonging to the south and North-Frontier. Augments in income inequality generate weak institutions and so low rates of growth, moreover in these conditions the 
country takes longer to get out of a crisis, even in the case it is originated in the international scope.

Results on economic convergence were not uniform, but the fact that significant cases on convergence are major in the second stage gives signal that regional equality can be improving. It will be possible to infer that trade opening is helping to diminish the income inequalities in Mexico? Some previous investigations have concluded that yes (German-Soto and Chapa Cantu, 2015), while other find that only marginally it has been reduced (Levy and Walton, 2009). While some evidence is obtained from this work, more investigation on this theme should be addressed with the aim to reinforce the conclusions applying different techniques, methodologies and improved databases.

\section{ACKNOWLEDGEMENTS}

Authors acknowledge the financial support by the Autonomous University of Coahuila to carry out this project, at the participants of a congress on Seminar of Investigation realized in Saltillo, Mexico, and two anonymous referees for useful comments that helped to enrich the final version of this work.

\section{REFERENCES}

Azariadis, Costas. 1996. "The Economics of Poverty Traps Part One: Complete Markets." Journal of Economic Growth 1(4):449496. http://dx.doi.org/10.1007/BF00150197

Badinger, Harald; Müller, Werner, and Tondl, Gabriele. 2004. "Regional Convergence in the European Union, 1985-1999: A Spatial Dynamic Panel Analysis." Regional Studies 38(3):241-253.

http://dx.doi.org/10.1080/003434042000211105

Barberá, Rafael A. and Doncel, Luis M. 2003. La Moderna Economía del Crecimiento, Madrid: Síntesis.

Barro, Robert J. and Sala-i-Martin, Xavier. 1991. "Convergence across States and Regions." Brookings Papers on Economic Activity 1:107-158. http://dx.doi.org/10.2307/2534639

Barro, Robert J. and Sala-i-Martin, Xavier. 2004. Economic Growth, Cambridge: The MIT Press.

Ben-David, Dan. 1998. "Convergence Clubs and Subsistence Economies." Journal of Development Studies 55(1):155-171. http://dx.doi.org/10.1016/s0304-3878(97)00060-6

Bernard, Andrew B. and Durlauf, Steven N. 1995. "Convergence in International Output." Journal of Applied Econometrics 10:97-108.

http://dx.doi.org/10.1002/jae.3950100202

Berthelemy, Jean C. and Varoudakis, Aristomene. 1996. "Economic Growth, Convergence Clubs, and the Role of Financial Development." Oxford Economic Papers 48(2):300-328. http://dx.doi.org/10.1093/oxfordjournals.oep.a028570

Bianchi, Marco. 1997. "Testing for Convergence: Evidence from NonParametric Multimodality Tests." Journal of Applied Econometrics 12(4):393-409. http://dx.doi.org/10.1002/(SICl)10991255(199707)12:4<393::AID-JAE447>3.0.CO;2-J
Carlino, Gerald. A. and Mills, Leonard. 1993. "Are U.S. Regional Incomes Converging? A Time Series Analysis." Journal of Monetary Economics 32:335-346. http://dx.doi.org/10.1016/0304-3932(93)90009-5

Chatterji, Monojit. 1992. "Convergence Clubs and Endogenous Growth." Oxford Review of Economic Policy 8(4):57-69. http://dx.doi.org/10.1093/oxrep/8.4.57

Crafts, Nicholas. 1999. "Economic Growth in the Twentieth Century." Oxford Review of Economic Policy 15(4):18-34. http://dx.doi.org/10.1093/oxrep/15.4.18

Deardorff, Alan V. 2001. "Rich and Poor Countries in Neoclassical Trade and Growth." The Economic Journal 111(470):277294. http://dx.doi.org/10.1111/1468-0297.00608

Ertur, Cem; Le Gallo, Julie, and Baumont, Catherine. 2006. "The European Regional Convergence Process, 1980-1995: Do Spatial Regimes and Spatial Dependence Matter?" International Regional Science Review 29(1):3-34. http://dx.doi.org/10.1177/0160017605279453

Evans, Paul and Karras, Georgios. 1996. "Convergence Revisited." Journal of Monetary Economics 37:249-265. http://dx.doi.org/10.1016/S0304-3932(96)90036-7

Fischer, Manfred M. 2011. "A Spatial Mankiw-Romer-Weil Model: Theory and Evidence." The Annals of Regional Science 47(2):419-436.

http://dx.doi.org/10.1007/s00168-010-0384-6

German-Soto, Vicente and Chapa Cantú, Joana C. 2015 "Cointegration with Structural Changes between per capita Product and Income Inequality in Mexico." Applied Economics 47(49):5215-5228. http://dx.doi.org/10.1080/00036846.2015.1044649

German-Soto, Vicente. 2005. "Generación del Producto Interno Bruto Mexicano por Entidad Federativa, 1940-1992." El Trimestre Económico 72(287):617-653.

German-Soto, Vicente. 2008. "El Stock de Capital Industrial Medido a Través de la Relación Inversión-Empleo: Estimaciones para los Estados Mexicanos." Ensayos. Revista de Economía 27(1):53-80.

German-Soto, Vicente. 2013. Metodología para Generar Información Regional. Aplicación a la Industria Mexicana, México: Plaza y Valdés.

Germán-Soto, Vicente; Rodríguez Pérez, Reyna E. and Escamilla Jiménez, Carmen N. 2013. "Acumulación y Desigualdad del Capital Humano entre los Estados Mexicanos Durante 19602008." Paradigma Económico 5(2):5-31.

Grossman, Gene M. and Helpman, Elhanan. 1991. Innovation and Growth in the Global Economy, Cambridge: The MIT Press.

Guerrieri, Paolo. 1990. Las Fluctuaciones Económicas, Barcelona: Oikos-Tau.

Hammond, George W. 2006. "A Time Series Analysis of U.S. Metropolitan and non-Metropolitan Income Divergence." The Annals of Regional Science 40:81-94. http://dx.doi.org/10.1007/s00168-005-0029-3

Hobijn, Bart and Franses, Philip H. 2000. "Asymptotically Perfect and Relative Convergence of Productivity." Journal of Applied Econometrics 15(1):59-81. http://dx.doi.org/10.1002/(SICl)10991255(200001/02)15:1<59::AID-JAE544>3.0.CO;2-1

Islam, Nazrul. 1995. "Growth Empirics: A Panel Data Approach." Quarterly Journal of Economics 110(4):1127-1170. http://dx.doi.org/10.2307/2946651

Jones, Charles I. 2000. Introducción al Crecimiento Económico, México: Pearson Educación.

Kleinbaum, David G.; Kupper, Lawrence L.; Nizam, Azhar and Muller, Keith E. 2008. Applied Regression Analysis and other Multivariate Methods, U.S.: Duxbury Press. 
Lee, Kevin; Pesaran, M. Hashem and Smith, Ron. 1997. "Growth and Convergence in a Multi-Country Empirical Stochastic Solow Model." Journal of Applied Econometrics 12:357-392. http://dx.doi.org/10.1002/(SICI)10991255(199707)12:4<357::AID-JAE441>3.0.CO;2-T

Levy, Santiago and Walton, Michael. 2009. "Equity, Competition, and Growth in Mexico: An Overview." In No Growth without Equity? Equity, Competition, and Growth in Income inequality in Mexico edited by S. Levy and M. Walton. Washington: Palgrave Macmillan and the World Bank.

$\mathrm{Li}$, Qing and Papell, David. 1999. "Convergence of International Output Time Series Evidence for 16 OECD Countries." International Review of Economics and Finance 8:267-280. http://dx.doi.org/10.1016/S1059-0560(99)00020-9

Lu, Shengrong and Wang, Yanwu. 2015. "Convergence, Technological Interdependence and Spatial Externalities: A Spatial Dynamic Panel Data Analysis." Applied Economics 47(18):1833-1846.

http://dx.doi.org/10.1080/00036846.2014.1000523

Lucas, Robert E. 1988. "On the Mechanics of Economic Development." Journal of Monetary Economics, 22(1):3-42. http://dx.doi.org/10.1016/0304-3932(88)90168-7

Mankiw, N. Gregory; Romer, David and Weil, David N. 1992. "A Contribution to the Empirics of Economic Growth." Quarterly Journal of Economics 107(2):407-437. http://dx.doi.org/10.2307/2118477

Montañés Antonio; Olloqui, Irene and Calvo, Elena. 2005. "Selection of the Break in the Perron-Type Test." Journal of Econometrics 129:41-64. http://dx.doi.org/10.1016/j.jeconom.2004.09.003

Nahar, S. and Inder Brett. 2002. "Testing Convergence in Economic Growth for OECD Countries." Applied Economics 34:20112022.

http://dx.doi.org/10.1080/00036840110117837
$\mathrm{Ng}$, Serena and Perron, Pierre. 1995. "Unit Root Tests in ARMA Models with Data-Dependent Methods for the Selection of the Truncation Lag." Journal of the American Statistical Association 90:268-281.

http://dx.doi.org/10.1080/01621459.1995.10476510

$\mathrm{Ng}$, Serena and Perron, Pierre. 2001. "Lag Length Selection and the Construction of Unit Root Tests with Good Size and Power." Econometrica 69(6):1519-1554. http://dx.doi.org/10.1111/1468-0262.00256

Nonneman, Walter and Vanhoudt, Patrick. 1996. "A Further Augmentation of the Solow Model and the Empirics of Economic Growth for OECD Countries." Quarterly Journal of Economics, 111(3):943-953. http://dx.doi.org/10.2307/2946677

Quah, Danny T. 1996. "Empirics for Economic Growth and Convergence." European Economic Review 40(6):13531375. http://dx.doi.org/10.1016/0014-2921(95)00051-8

Rey, Sergio J. and Montouri, Brett D. 1999. "US Regional Income Convergence: A Spatial Econometric Perspective." Regional Studies 33(2):143-156. http://dx.doi.org/10.1080/00343409950122945

Romer, Paul M. 1986. "Increasing Returns and Long-Run Growth." Journal of Political Economy 94:1002-1037. http://dx.doi.org/10.1086/261420

Solow, Robert. 1956. "A Contribution to the Theory of Economic Growth." Quarterly Journal of Economics 70(1):65-94. http://dx.doi.org/10.2307/1884513

Yau, Ruey and Hueng, C. James. (2007). "Output Convergence Revisited: New Time Series Results on Industrialized Countries." Applied Economics Letters 14:75-77. http://dx.doi.org/10.1080/13504850500425543

\section{DOI: http://dx.doi.org/10.6000/1929-7092.2016.05.04}

(C) 2016 German-Soto and Salazar; Licensee Lifescience Global.

This is an open access article licensed under the terms of the Creative Commons Attribution Non-Commercial License (http://creativecommons.org/licenses/by-nc/3.0/) which permits unrestricted, non-commercial use, distribution and reproduction in any medium, provided the work is properly cited. 